\title{
SIMILARITIES AND DIFFERENCES IN EPIDEMIOLOGY AND RISK FACTORS OF CEREBRAL AND MYOCARDIAL ISCHEMIC DISEASE
}

Angelina Stevanovic ${ }^{1}$, Danijela Tasic ${ }^{2}$, Nebojsa Tasic ${ }^{2}$, Dalibor Dragisic ${ }^{3}$, Miroslav Mitrovic ${ }^{1}$, Marina Deljanin-Ilic ${ }^{4}$, Stevan Ilic ${ }^{4}, Z_{\text {Zoran }}$ Citakovic $^{5}$ ${ }^{1}$ Hispa - Hypertension, infarction \& stroke prevention association, Belgrade Serbia

${ }^{2}$ Dedinje Cardiovascular Institute, School of Medicine, Belgrade, Serbia ${ }^{3}$ Clinical Hospital Centre "Dragisa Misovic", Belgrade, Serbia ${ }^{4}$ Institute for rehabilitation „Niska Banja“, Nis ${ }^{5}$ General Hospital, Uzice

\section{SLIČNOSTI I RAZLIIE U EPIDEMIOLO GIJI I FAITORIMA RIZIKA CEREBRALNE I MIOKARDNE ISHEMIJSKE BOLESTI}

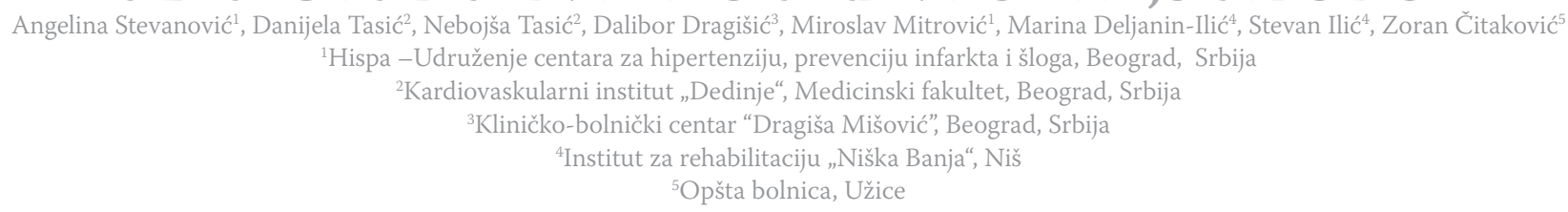

\section{ABSTRACT}

Ischemic heart disease and cerebral ischemia represent the leading causes of mortality worldwide. Both entities share risk factors, pathophisiology and etiologic aspects by means of a main common mechanism, atherosclerosis.

The autors aimed to investigate differences and similarities in epidemiology and risk factors that could be found between both entities.

In a retrospective sudy 403 patients were included and divided into two groups: group of 289 patients with history of myocardial infarction (AMI), and group of 114 patients with history of ischemic stroke (IS). All patients were evaluated for nonmodifiable risk faktors, which included age and sex, and modifiable, such as hypertension, dyslipidemia, diabetes, obesity, physical activity and smoking. Differences in some epidemiological aspects were also considered: occupation, marital status, alcohol consumption, exposure to stress.

Patients with history of IS were significantly older then AMI patients (64.0 \pm 9.9 vs $64.0 \pm 9.9, p=0,028)$, with higher diastolic blood pressure $(87,1 \pm 10,2$ vs $83,6 \pm 10,4, p=0,003)$ and higher Sokolow-Lyon index in ECG, an also index of left ventricular hypertrophy $(19,2 \pm 9,1$ vs $14,7 \pm 6,5)$. There were no significant differences between groups in the estimated body mass index and waist circumference. Differences between groups in stress exposure, occupation, alcohol consumption or physical activity were no significant. Patients in AMI group were more frequently male (199 (69\%) vs 59 (52\%), $p=0,001)$, married (252 (87\%) vs 88 (77\%), $p=0,037$ ), smokers (162 (56\%) vs 50 (44\%), $p=0,018$ ) and with higher incidence od dyslipidemia (217 (75\%) vs 73 (64\%), $p=0,019)$ compared with IS group. Incidence of arterial hypertension and diabetes was similar in both groups.

Both entities share similar pathophysiological mechanisms and, consequently, main traditional risk factors. However, incidence of myocardial infarction increases with male sex, dyslipidemia, smoking and marital status, while incidense of ischemic stroke increases with age, higher diastolic blood pressure and also with ECG signs of left ventricular hypertrophy.

Keywords: Ischemic heart disease, mortality,

hypertension 


\section{INTRODUCTION}

Cerebral and myocardial ischemic disease share similar risc factors and pathophysiology and represent the consequence of atherothrombosis as an main etiological factor. About $87 \%$ of all strokes are ischemic strokes, in which blood flow to the brain is blocked [1]. Both entities represent the leading causes of mortality worldwide. Coronary artery disease (CAD) is a leading cause of death or disability in both, men and women. According to the World Health Organization (WHO), in 2002 there were 7.22 million deaths from coronary artery disease globally. [2]

Coronary artery disease alone is the most common cause of death in Europe, accounting for nearly 2 million deaths each year. More than 1 in 5 deaths of women (22 percent) and men (21 percent) are from CAD [3].

Stroke is also a major cause of death and a leading cause of serious long-term disability $[4,5]$.

According to WHO estimates, 15 million people each year suffer from strokes and 5 million people are left permanently disabled. [2] Based on report of American Heart Association in the Heart Disease and Stroke Statistics 2012 Update, the average age for the incidence of a stroke is $>75$ years for women, and 71 years for men [4].

Stroke risk increases with age, but strokes can occur at any age. Compared to older people young adults are at a lower risk of stroke, however incidence of stroke in young people ranges from 60 to 200 new cases per year per million inhabitants. By the age of 75, 1 in 5 women and 1 in 6 men will have a stroke [6, 7].

Previous study [8] reported a yearly increase in frequency of stroke from 2.4 per 100,000 for a person aged between 20 and 24 years, to 4.5 per 100,000 for a person aged between 30 and 34 years, and to 32.9 per 100,000 for a person aged $45-49$ years. Incidence of stroke was slightly higher in women younger than 30 years and in men older than 35 years.

Although coronary heart disease and stroke share important risk factors, some risk factors appears to have a stronger association with risk of stroke, such as high blood pressure, whereas others, for example total cholesterol, may have a stronger association with risk of coronary heart disease [9-13].

Luckily, although not curable, cardiovascular diseases are largely preventable. Modification of 9 easily measured clinical and laboratory risk factors can prevent up to $90 \%$ of first myocardial infarctions [14]. The long-recognized risk factors include age, sex, blood pressure, cholesterol levels, smoking status, diabetes mellitus, obesity, and a sedentary lifestyle. In addition, chronic kidney disease and insulin resistance (pre-diabetes) can be important risk factors for coronary heart disease, such as atrial fibrillation for stroke.

Unfortunately, the previous studies have demonstrated that coronary artery disease increases the risk for stroke, whereas patients with stroke are more likely suffer from coronary artery disease [15-18].
In present study the differences and similarities in epidemiology and risk factors that could be found in between both entities were analyzed and discussed.

\section{MATERIALS AND METHODS}

This observational, multicenter, epidemiological study consisted of 403 patients divided into two groups: group of 289 patients with history of myocardial infarction (AMI), and group of 114 patients with history of ischemic stroke (IS).

Patients were recruited from primary care facilities and outpatient cardiology clinics, part of the Hypertension, infarction and stroke prevention association (HISPA).

All subjects involved in the study went through clinical examination, anthropometry and blood pressure measurements, electrocardiography, and laboratory tests, which included parameters of metabolic control and diabetic status.

The body mass index (BMI) was calculated as body weight (in kilograms) divided by height (in meters squared), while systolic and diastolic blood pressure (SBP/DBP) values were meassured in the sitting position. Waist size was meassured too in all patients.

Patients were evaluated for nonmodifiable risk faktors, which included age and sex, and modifiable, such as hypertension, dyslipidemia, diabetes, obesity, physical activity and smoking. Differences in some epidemiological aspects were also considered: marital status, alcohol consumption, exposure to stress.

\section{STATISTICAL ANALYSIS}

All statistical analyses were performed by SPSS for Windows (SPSS version 20.0, Inc., Chicago, IL, USA). All statistical tests were two-tailed, in which a p-value of $<0.05$ was considered significant.

Continuous data are presented as mean \pm standard deviation when normally distributed (as assessed by the Kolmogorov-Smirnov test) and as a median when nonnormally distributed. Categorical data are presented as frequencies and percentages.

The data were compared between groups by an unpaired t-test for continuous variables. Categorical variables were compared by nonparametric tests.

\section{RESULTS}

The study population consisted of 403 patents, mean age $64.7 \pm 9.8$ years; 258 (64\%) men and 145 (36\%) women.

The general characteristics of the study groups are presented in Table 1.

Patients with history of IS were significantly older then AMI patients. Diastolic office blood pressure (DBP) 
Table 1 General characteristics of patients

\begin{tabular}{lccc} 
& \multicolumn{3}{c}{ Groups } \\
\hline & $\begin{array}{c}\text { AMI } \\
(\mathrm{n}=289)\end{array}$ & $\begin{array}{c}\text { IS } \\
(\mathrm{n}=114)\end{array}$ & $\mathbf{p}$ \\
\hline Age (years) & $64.0 \pm 9.9$ & $66.3 \pm 9.3$ & $\mathbf{0 . 0 2 8}$ \\
$\begin{array}{l}\text { Sex, male/female } \\
(\% \text { male })\end{array}$ & $199 / 90(68.9 \%)$ & $59 / 55(51.8 \%)$ & $\mathbf{0 . 0 0 1}$ \\
SBP $(\mathrm{mmHg})$ & $139.2 \pm 19.9$ & $142.7 \pm 22.6$ & 0.127 \\
DBP $(\mathrm{mmHg})$ & $83.6 \pm 10.4$ & $87.1 \pm 10.2$ & $\mathbf{0 . 0 0 3}$ \\
Heart rate $($ bit/min) & $69.4 \pm 9.9$ & $71.3 \pm 13.2$ & $\mathbf{0 . 2 3 1}$ \\
$\begin{array}{l}\text { Sokolow-Lyon } \\
\text { index in ECG }\end{array}$ & $14.7 \pm 6.5$ & $19.2 \pm 9.1$ & $\mathbf{0 . 0 4 7}$ \\
BMI (kg/m $\left.{ }^{2}\right)$ & $29.0 \pm 4.1$ & $28.1 \pm 5.0$ & 0.103 \\
Waist size $(\mathrm{cm})$ & $100.2 \pm 11.7$ & $100.7 \pm 14.1$ & 0.791 \\
\hline
\end{tabular}

Results are shown as a mean \pm standard deviation, SBP-systolic blood pressure, DBP-diastolic blood pressure, BMI-body mass index, ECG electrocardiography, $\left(^{*}\right)$ significant at the 0.05 level, $\left({ }^{*}\right)$ at the level 0.01

Table 2 Modifiable risk faktors and epidemiological aspects

\begin{tabular}{lccc} 
& \multicolumn{3}{c}{ Groups } \\
\hline & $\begin{array}{c}\text { AMI } \\
(\mathrm{n}=289)\end{array}$ & $\begin{array}{c}\text { IS } \\
(\mathrm{n}=114)\end{array}$ & $\mathbf{p}$ \\
\hline $\begin{array}{l}\text { Hypertension, n (\%) } \\
\text { Diabetes, n (\%) }\end{array}$ & $270(93.4 \%)$ & $106(93.0 \%)$ & 0.513 \\
$\begin{array}{l}7 y \text { slipidemia } \\
\text { Dyslipidemia, n (\%) }\end{array}$ & $217(75.1 \%)$ & $73(64.0 \%)$ & $\mathbf{0 . 0 1 9}$ \\
$\begin{array}{l}\text { Smoking, n (\%) } \\
\text { Family history, n (\%) }\end{array}$ & $238(52.4 \%)$ & $98(86.0 \%)$ & $\mathbf{0 . 2 3 5}$ \\
$\begin{array}{l}\text { Alcohol } \\
\text { consumption, n (\%) }\end{array}$ & $20(6.9 \%)$ & $7(6.1 \%)$ & 0.487 \\
$\begin{array}{l}\text { Exposure to stress, } \\
\text { n (\%) }\end{array}$ & $168(58.1 \%)$ & $67(58.8 \%)$ & 0.499 \\
$\begin{array}{l}\text { Marital status, } \\
\text { married n (\%) }\end{array}$ & $252(87 \%)$ & $88(77 \%)$ & $\mathbf{0 , 0 3 7}$ \\
\hline
\end{tabular}

$\left({ }^{*}\right)$ significant at the 0.05 level, $\left({ }^{*}\right)$ at the level 0.01 was found to be significantly higher in IS patients, and Sokolow-Lyon index in ECG, as a index of left ventricular hypertrophy, also was found to be significantly higher in the same group of patients. There were no significant differences between groups in the estimated body mass index and waist size.

Patients with AMI were more frequently male, while gender distribution in IS group were found to be almost equal.

Table 2 displays comparison of well established modifiable risk faktors and some epidemiological aspects between the groups.

Patients in AMI group were more frequently married, smokers and with higher incidence od dyslipidemia compared to SI group. Incidence of arterial hypertension, diabetes, family history, alcohol consumption and exposure to stress was similar in both groups.

A significant difference in physical activity, which was graded in five levels, was not found $\left(\mathrm{X}^{2}=3.028, \mathrm{p}=0.082\right)$.

Table 2 displays general characteristics of patients and nonmodifiable and modifiable cardiovascular risk faktors adjusted by gender.

Men who suffered from AMI were significantly older, more frequent smokers and alcohol users, while men who suffered from IS had higher values of diastolic blood pressure and also were more alcohol users compared to women.

\section{DISCUSSION}

Overall, results indicates substantial similarities of modifiable risk factors with coronary heart disease (CHD) and stroke.

Table 3 General caracteristic and cardiovascular risk factors adjusted by gender

\begin{tabular}{|c|c|c|c|c|c|c|}
\hline & \multicolumn{2}{|c|}{ AMI } & \multicolumn{4}{|c|}{ IS } \\
\hline & male & female & $\mathrm{p}$ & male & female & $\mathrm{p}$ \\
\hline Age (years) & $63 \pm 9.87$ & $66 \pm 9.47$ & 0.004 & $65 \pm 11.1$ & $67 \pm 6.7$ & 0.262 \\
\hline SBP (mmHg) & $138 \pm 18.9$ & $141 \pm 21.9$ & 0.329 & $146 \pm 22.5$ & $140 \pm 22.4$ & 0.156 \\
\hline $\mathrm{DBP}(\mathrm{mmHg})$ & $84 \pm 9.7$ & $83 \pm 11.9$ & 0.396 & $89 \pm 10.9$ & $85 \pm 9.0$ & 0.014 \\
\hline Heart rate (bit/min) & $70 \pm 10.9$ & $68 \pm 7.4$ & 0.245 & $71 \pm 8.7$ & $72 \pm 16.8$ & 0.778 \\
\hline Sokolow-Lyon index & $14.9 \pm 6.8$ & $14.3 \pm 6.2$ & 0.812 & $16 \pm 8.4$ & $21 \pm 9.4$ & 0.296 \\
\hline BMI $\left(\mathrm{kg} / \mathrm{m}^{2}\right)$ & $29 \pm 3.7$ & $29 \pm 4.8$ & 0.456 & $29 \pm 4.2$ & $28 \pm 5.7$ & 0.264 \\
\hline Waist size $(\mathrm{cm})$ & $102 \pm 11.2$ & $96 \pm 11.6$ & $<0.001$ & $106 \pm 13.6$ & $96 \pm 13.2$ & 0.007 \\
\hline Hypertension, n (\%) & $184(92.5)$ & $86(95.6)$ & 0.239 & $54(91.5)$ & $52(94.5)$ & 0.398 \\
\hline Diabetes, $\mathrm{n}(\%)$ dyslipidemia & $51(25.6)$ & $26(28.9)$ & 0.329 & $15(25.4)$ & $14(25.5)$ & 0.583 \\
\hline Dyslipidemia, n (\%) & 151(75.9) & $66(73.3)$ & 0.373 & $35(59.3)$ & $38(69.1)$ & 0.187 \\
\hline Smoking, $\mathrm{n}(\%)$ & $123(61.8)$ & $39(43.3)$ & 0.003 & $30(50.8)$ & $20(36.4)$ & 0.085 \\
\hline Family history, n (\%) & $165(82.9)$ & $73(81.1)$ & 0.413 & $52(88.1)$ & $46(83.6)$ & 0.337 \\
\hline Alcohol consum., n (\%) & $20(10.1)$ & 0 & $<0.001$ & $7(11.9)$ & 0 & 0.008 \\
\hline Stress, n (\%) & $117(58.8)$ & $51(56.7)$ & 0.416 & $31(52.5)$ & $36(65.5)$ & 0.113 \\
\hline Married n (\%) & $180(90.5)$ & $72(80.0)$ & 0.013 & $47(79.7)$ & $41(74.5)$ & 0.334 \\
\hline
\end{tabular}

Results are shown as a mean \pm standard deviation, SBP-systolic blood pressure, DBP-diastolic blood pressure, BMI-body mass index, $\left({ }^{*}\right)$ significant at the 0.05 level, $\left(^{*}\right)$ at the level 0.01 


\section{MODIFIABLE RISK FAKTORS} AND EPIDEMIOLOGICAL ASPECTS

Previous investigations have found that hypertension has a generally stronger association with risk of stroke versus CHD, whereas cholesterol has a generally stronger influence on risk of CHD [19, 20].

Hypertension is a main risk factor not only for hemorraghic stroke but also for IS [21]. According to data from the Sagrat Cor of Barcelona Stroke Registry (2704 patients with ischemic stroke), hypertension was the main risk factor in the different age groups [7].

In a study conducted by Ihle-Hansen et al [23] $60 \%$ of patients with stroke $(126 / 210)$ had hypertension, while in a study conducted by Putaala et al. [24] 39\% of patients (389/990) had hypertension.

In our study incidence of hypertension in group of IS patients was significantly higher in comparison to previous investigations, even $93 \%$ of patients with IS had hypertension (106/114). Incidence of hypertension was similar in bouth our study groups, but value of diastolic blood pressure was significantly higher in IS group. Men who suffered from IS in our study had higher values of diastolic blood pressure and also were more alcohol users compared to women.

Dyslipidemia is a major risk factor for atherosclerosis and atherosclerotic based diseases [25]. Serum cholesterol has generally strong influence on risk of CHD [19], and is positively related to coronary heart disease morbidity and mortality [26].

In our study dyslipidemia was significantly frequent in group of AMI patients compared to patients who suffered from IS.

Diabetes mellitus is well-established risk factor for cardiovascular disease, but also an independent risk factor of ischemic stroke of atherothrombotic cause [27]. Dyslipidemia, hypertension and obesity are atherogenic risk factors frequently found in type 2 diabetes patients [28, 29]. The combination of hypercholesterolemia and hypertension increases the frequency of vascular complications in patients with diabetes.

Incidence of diabetes in our study was equal in both groups.Abdominal obesity is defined by a waist circumference $>102 \mathrm{~cm}$ in men and 88 in women [41]. Unfortunately a lot of our patients were overweight and obese. This is an important finding due to the fact that weight and abdominal fat reduction is associated with a lowering in blood pressure, and may thereby reduce the risk of stroke,

A great deal of evidence over the last few decades has confirmed that cigarette smoking is an independent predictor of cerebrovascular disease in both gender. Smokers have a significantly higher risk of ischemic stroke compared to non-smokers. Finally, there is an indication that passive cigarette smoker have highest risk of stroke. It is known that smoking increases the risk of atherosclerosis, also causing thrombosis in narrow arterial vessels. Smoking have contrabutin in the onset of endothelial dysfunc- tion, increase in blood viscosity, and platelet aggregation [30-32].

Patients who suffered from AMI in our study were more frequently smokers compared to IS group, predominantly men who were significantly older, more frequently smokers and alcohol users compared to women.

Physical activity reduces the risk of cardiovascular disease, premature death and stroke [33].

Based on data from a large population-based case-control study conducted in Stockholm, Sweden, 1992-1994 investigators concluded that aerobic physical activity such as exercise or walking at work seemed to reduce the risk of myocardial infarction, whereas anaerobic activity such as heavy lifting at work were related to increased risk of myocardial infarction.

According to data collected from 23 corresponding studies, there is strong evidence that subjects with high physical activity as compared to those with low physical activity had a lower stroke risk [34].

A significant difference in physical activity, which was graded in five levels, was not found between groups in our study.

The evidence from previous studies suggest that stressful life events, specially acute psychological stress factors contribute independently to the risk of coronary heart disease $[35,36]$ and have been shown to be independent predictive factors of CHD [37].

Stress may be a trigger for neuroendocrine and platelet activation and directly affect CHD, or may cause adverse health behaviors such as smoking, poor diet, and sedentary lifestyle, which increases the risk of CHD [38].

In our study stress exposure were significant, almost equall in both groups, $58.1 \%$ in AMI and 58,8\% in IS group.

In the study conducted by Tulio et al. [39], left ventricular hypertrophy and abnormal left geometry were independently associated with increased stroke risk. Left ventricular hypertrophy is strongly associated with ischemic stroke in all age, sex, and race-ethnic subgroups.

In our study left ventricular hypertrophy was estimated with Sokolow-Lyon index by electrocardiography, as an index of left ventricular hypertrophy wich was significantly higher in IS group.

\section{NONMODIFIABLE RISK FAKTORS}

Incidence of coronary heart disease in male is well recognised. Cardiovascular disease develops 7 to 10 years later in women than in men [39].

In accordance with previous studies, in our study patients in AMI group were more frequently male and significantly younger compared to female.

The coronary heart disease event rate in women is low and predominantly attributed to smoking before menopause, Smoking increases the risk of a first acute myocardial infarction more pronounced in females compared to male [42]. 
However, in our study male were more frequent smokers compared to female.

The incidence of stroke increases significantly with age, and is higher in men up to age 75, similar in the 75-84 age group, and higher in women in the age group greater than 85 [43].

Despite the higher risk in men, the lifetime risk of stroke is higher in women. The Framingham study calculated lifetime risk of stroke among middle age men and women and found that the lifetime risk in women age 55 was $21 \%$ and in men age 55, 17\% [44].

In our sudy IS patients were significantly older compared to AMI group, but without significant difference in age between men and women in IS group. Men who suffered from IS had higher values of diastolic blood pressure and were more alcohol users compared to women.

Hypertension associated with age represents leading risk factors for cerebrovascular disease and also multiply the risk for stroke $[45,46]$.

\section{CONCLUSION}

Both entities share similar pathophysiological mechanisms and, consequently, main traditional risk factors. However, the majority of cardiovascular risk factors show no important differences between the groups. Incidence of myocardial infarction increases with male sex, dyslipidemia, smoking and marital status, while incidence of ischemic stroke increases with age, higher diastolic blood pressure and also with ECG signs of left ventricular hypertrophy.

\section{REFERENCES}

1. Mozzafarian D, Benjamin EJ, Go AS, Arnett DK, Blaha MJ, Cushman M, et al., on behalf of the American Heart Association Statistics Committee and Stroke Statistics Subcommittee. Heart disease and stroke statistics-2016 update: a report from the American Heart Association. Circulation 2016;133(4):e38-360.

2. Atlas of Heart Disease and stroke, WHO, Sept. 2004.

3. British Heart Foundation. European Cardiovascular Disease Statistics, 2000 Edition.

4. Roger V L, Go A S, LLoyd-Jones D M, Benjamin E J, Berry J D et al. Heart Disease and Stroke Statistics-2012 Update: a report from the American Heart Association. Circulation 125: e2-e220.

5. Mozaffarian D, Benjamin EJ, Go AS, Arnett DK, Blaha MJ, et al. Heart disease and stroke statistics-2015 update: a report from the American Heart Association. Circulation 2015;131(4):e29-322.

6. Katsnelson M, Della-Morte D, Rundek T. Stroke in young. Peiolog. 2012; 114 (3): 347-353.

7. State of the Nation Stroke statistics - January 2016. Stroke association.
8. Putaala J, Metso A J, Metso T M, Konkola N, Kraemer Y et al. 2009 Analysis of 1008 consecutive patients aged 15 to 49 with first-ever ischemic stroke: the Helsinki young stroke registry. Stroke 40: 1195-1203.

9. Office for National Statistics. Mortality statistics: DHI Series no. 342001 and Series DH2 no. 29. London: Office for National Statistics, 2002.

10. World Health Organization. Statistical information (WHOSIS). Geneva: WHO, 2004.

11. Petersen S, Peto V, Rayner M. Coronary heart disease statistics 2004. London: British Heart Foundation, 2004.

12. Marmot M, Elliott P, eds. Coronary heart disease epidemiology. Oxford: Oxford University Press, 1997.

13. Health Survey for England 2002. http: // www. publications. doh. gov. Uk /stats / trends1. htm.

14. Yusuf S, Hawken S, Ounpuu S, Dans T, Avezum A, Lanas $F$, et al. Effect of potentially modifiable risk factors associated with myocardial infarction in 52 countries (the INTERHEART study): case-control study. Lancet 2004;364(9438):937-52.

15. Gongora-Rivera F, Labreuche J, Jaramillo A, Steg PG, Hauw JJ, Amarenco P. Autopsy prevalence of coronary atherosclerosis in patients with fatal stroke. Stroke 2007; 38: 1203-10.

16. Touzé E, Varenne O, Calvet D, Mas JL. Coronary risk stratification in patients with ischemic stroke or transient ischemic stroke attack. Int J Stroke 2007; 2: 177-83.

17. Coca A, Messerli FH, Benetos A, et al. Predicting stroke risk in hypertensive patients with coronary artery disease: a report from the INVEST. Stroke 2008; 39: 343-8.

18. De Silva DA, Woon FP, Moe KT, Chen CL, Chang HM, Wong MC. Concomitant coronary artery disease among Asian ischaemic stroke patients. Ann Acad Med Singapore 2008; 37: 573-5.

19. Wilson PW, D'Agostino RB, Levy D, et al. Prediction of coronary heart disease using risk factor categories. Circulation 1998;97:1837-47.

20. Wolf PA, D’Agostino RB, Belanger AM, et al. Probability of stroke: a risk profile from the Framingham Study. Stroke1991;3:312-18.

21. Kannel Wb, Wolf PA, Verter J, mcMara P. Framingham Studyinsights on the hazards of elevated blood pressure. JAMA 2008; 300: 2545-7.

22. Arboix A, García-Eroles L, Comes E, Oliveres M, Targa C, Balcells M, Pujadas R, Massons J. Importance of cardiovascular risk profile for in-hospital mortality due to cerebral infarction. Rev Esp Cardiol 2008; 61: 1020-1029

23. Ihle-Hansen H, Thommessen B, Wyller TB, Engedal K, Fure B. Risk factors for and incidence of subtypes of ischemic stroke. Funct Neurol. 2012;27(1):35-40.

24. Putaala J, Haapaniemi E, Kaste M, Tatlisumak T. How does number of risk factors affect prognosis in young patients with ischemic stroke?. Stroke. 2012;43(2):356-61. 
25. Juonala M, Viikari JS, Kahonen M, Solakivi T, Helenius $\mathrm{H}$, Jula A, et al. Childhood levels of serum apolipoproteins $\mathrm{B}$ and A-I predict carotid intima-media thickness and brachial endothelial function in adulthood: the cardiovascular risk in young Finns study. J Am Coll Cardiol. 2008;52(4):293-9.

26. Lavados PM, Sacks C, Prina L, Escobar A, Tossi C, Araya F, et al. Incidence,30-day case-fatality rate, and prognosis of stroke in Iquique, Chile: a 2-year community-based prospective study (PISCIS project). Lancet. 2005;365(9478):2206-15.

27. Arboix A, Milian M, Oliveres M, García-Eroles L, Massons J. Impact of female gender on prognosis in type 2 diabetic patients with ischemic stroke. Eur Neurol 2006; 56: 6-12.

28. Marrugat J, Arboix A, García-Eroles L, Salas T, Vila J, Castell C, Tresserras R, Elosua R. [The estimated incidence and case fatality rate of ischemic and hemorrhagic cerebrovascular disease in 2002 in Catalonia]. Rev Esp Cardiol 2007; 60: 573-580.

29. The European Stroke Organisation (ESO) Executive Committee and the ESO Writing Committee. Guidelines for management of ischaemic stroke and transient ischaemic attack 2008. Cerebrovasc Dis 2008; 25: 457-507.

30. Burns DM. Epidemiology of smoking-induced cardiovascular disease. Prog Cardiovasc Dis 2003; 46: 11-29.

31. Underner M, Paquereau J, Meurice JC. [Cigarette smoking and sleep disturbance]. French Rev Mal Respir 2006; 23 (3 Suppl):6S67-6S77.

32. Lavie L, Lavie P. Smoking interacts with sleep apnea to increase cardiovascular risk. Sleep Med 2008; 9: 247-253.

33. Goldstein LB, Adams R, Alberts MJ, Appel LJ, Brass LM, Bushnell CD, Culebras A, Degraba TJ, Gorelick PB, Guyton JR, Hart RG, Howard G, Kelly-Hayes M, Nixon JV, Sacco RL. Primary prevention of ischemic stroke: a guideline from the American Heart Association/American Stroke Association Stroke Council: cosponsored by the Atherosclerotic Peripheral Vascular Disease Interdisciplinary Working Group; Cardiovascular Nursing Council; Clinical Cardiology Council; Nutrition, Physical Activity, and Metabolism Council; and the Quality of Care and Outcomes Research Interdisciplinary Working Group: the AmericanAcademy of Neurology affirms the value of this guideline. Stroke 2006; 37: 1583-1633.
34. Hankey GJ. Potential new risk factors for ischemic stroke: what is their potential? Stroke 2006; 37: 2181-2188

35. Rozanski A, Blumenthal JA, Davidson KW, et al. The epidemiology, pathophysiology, and management of psychosocial risk factors in cardiac practice: the emerging field of behavioral cardiology. J Am Coll Cardiol 2005;45:637-51.

36. Dimsdale JE. Psychological stress and cardiovascular disease. J Am Coll Cardiol 2008;51:1237-46.

37. Von Känel R. Psychological distress and cardiovascular risk: what are the links? J Am Coll Cardiol 2008;52:2163-5.

38. Rozanski A, Blumenthal JA, Kaplan J. Impact of psychological factors on the pathogenesis of cardiovascular disease and implications for therapy. Circulation 1999; 99:2192-217.

39. Tullio M, Zwas DR, Sacco RL, Sciacca RR, Homma S. Left Ventricular Mass and Geometry and the Risk of Ischemic Stroke. Stroke. 2003; 34:2380-2386.

40. Towfighi A, Zheng L, Ovbiagele B. Sex-specific trends in midlife coronary heart disease risk and prevalence. Arch Intern Med. 2009;169:1762-6.

41. Gustafson D. Adiposity indices and dementia. Lancet Neurol 2006; 5: 713-720.

42. Prescott E, Hippe M, Schnohr P, Hein HO, Vestbo J. Smoking and risk of myocardial infarction in women and men: longitudinal population study. BMJ. 1998; 316:1043-7.

43. Rosamond W, Flegal K, Friday G, Furie K et al. Heart disease and stroke statistics--2007 update: a report from the American Heart Association Statistics Committee and Stroke Statistics Subcommittee. Circulation. 2007 Feb 6;115(5):e69-171.

44. Seshadri S, Beiser A, Kelly-Hayes M, Kase CS, Au R, Kannel WB, Wolf PA. The lifetime risk of stroke: estimates from the Framingham Study. Stroke. 2006 Feb;37(2):345-5.

45. McGuinness B, Todd S, Passmore AP, Bullock R. Systematic review: Blood pressure lowering in patients without priorcerebrovascular disease for prevention of cognitive impairment and dementia. J Neurol Neurosurg Psychiatry 2008; 79: 4-5.

46. Mancia G. Prognostic value of long-term blood pressure variability: the evidence is growing. Hypertension 2011; 57 : 141-143 